\title{
Australia-Modified Karnofsky Performance Status 10
}

National Cancer Institute

\section{Source}

National Cancer Institute. Australia-Modified Karnofsky Performance Status 10. NCI

Thesaurus. Code C107493.

Comatose or barely arousable. 